une revue Gallia

Rhône-Alpes | 2009

\title{
La Chapelle-sous-Aubenas
}

Les Traverses

Christine Ronco

\section{(2) OpenEdition}

\section{Journals}

Édition électronique

URL : http://journals.openedition.org/adlfi/3413

ISSN : 2114-0502

Éditeur

Ministère de la culture

Référence électronique

Christine Ronco, «La Chapelle-sous-Aubenas », ADLFI. Archéologie de la France - Informations [En ligne], Rhône-Alpes, mis en ligne le 01 mars 2009, consulté le 30 avril 2019. URL : http://

journals.openedition.org/adlfi/3413

Ce document a été généré automatiquement le 30 avril 2019

(C) Ministère de la Culture et de la Communication, CNRS 


\title{
La Chapelle-sous-Aubenas
}

\author{
Les Traverses
}

\section{Christine Ronco}

\section{Identifiant de l'opération archéologique : 10093}

Date de l'opération : 2009 (EX)

Les 113 sondages réalisés au lieu-dit «les Traverses » n'ont livré que peu de vestiges archéologiques : seuls 10 sondages se sont révélés positifs. Ils s'organisent en deux zones principales. De la céramique non tournée a été retrouvée dans les sondages $23,26,27,28$, 32,35 et 36 . Les sondages 40,42 et 44 ont livré des structures à pierres chauffées circulaires, formant un alignement orienté nord-ouest sud-est. Le mobilier, limité à deux éléments lithiques, permet de proposer une datation du Néolithique final pour ces structures. Dans les autres sondages, l'étude du mobilier retrouvé dans les niveaux d'occupation a révélé deux phases chronologiques : l'une du Néolithique final, et l'autre des $\mathrm{V}^{\mathrm{e}} \mathrm{s}$.-début IV $\mathrm{e}$ s. avant notre ère. Il n'a toutefois pas été possible de reconnaître nettement deux niveaux distincts dans les stratigraphies. Même si elles restent ténues, ces observations ont révélé la présence d'occupations en place dans ce secteur de la plaine d'Aubenas, confirmant en cela les observations déjà effectuées par E. Durand, lors du diagnostic de la déviation RD 104.

2 Ronco Christine 
INDEX

Index géographique : Rhône-Alpes, Ardèche (07), Lachapelle-sous-Aubenas

Index chronologique : Néolithique final

Thèmes : galet aménagé

operation Expertise (EX)

\section{AUTEUR}

\section{CHRISTINE RONCO}

INRAP 